\title{
MOBILE LEARNING AND HEALTH EDUCATION: HOW STUDENTS OF BIOMEDICAL LABORATORY SCIENCES USE THEIR MOBILE DEVICES?
}

\author{
Teresa Cardoso ${ }^{1}$ and Renato Abreu ${ }^{1,2}$ \\ ${ }^{1}$ UID4372, LE@D, Laboratório de Educação a Distância e Elearning \\ Universidade Aberta, R. da Escola Politécnica, 147 - 1269-001 Lisboa, Portugal \\ ${ }^{2}$ ESTeSL, Escola Superior de Tecnologia da Saúde de Lisboa \\ Instituto Politécnico de Lisboa, Av. D. João II - Lote 4.69.01, 1990-096 Lisboa, Portugal
}

\begin{abstract}
Mobile Learning (M-learning) is an emerging area of distance education that takes advantage of the ubiquitous power of mobile devices, enabling the teaching and learning process by increasing access to information and supporting different types of learning. This article is part of a larger study, exploratory and descriptive, in which the use of mobile devices as a mediation tool in the teaching and learning process in a Portuguese higher school of health was analyzed. The instrument of data collection was a survey, which, in this case, 634 students responded to, with the aim of describing their use of mobile devices in learning contexts. From the data analysis, we perceive that the students mostly acquired their first mobile device at the age of 10 years old. Of these $98 \%$ use the Smartphone, mobile phone and tablet every day, and these mobile devices are of the following brands: Samsung (33\%), Apple (15\%), and Nokia (10\%). The Android operating system prevails (70\%) over iOS (15\%). The features of the mobile devices most used by the students were SMS, alarm clock, and Internet access, with percentages of use greater than or equal to $90 \%$. The importance attributed to the Apps for study and learning is indifferent or rejected for $72 \%$ of students. We can conclude, on account of our results, that the participants have, according to our perspective, the two conditions necessary to engage in mobile learning, namely: (i) positive perceptions about mobile devices, essentially in their ability to provide pedagogical advantages; (ii) owning a mobile device, meaning it is possible to implement a Bring your OWN device (BYOD) strategy.
\end{abstract}

\section{KEYWORDS}

M-learning, Mobile Devices, Students, Higher Education

\section{INTRODUCTION}

During 2010 the European Commission launched the Europe 2020 strategy, to guide the development of technological skills in order to carry out the economic and social objectives of the European Community in the long term. The European Digital Agenda, as part of this program, arises from the relevance of technologies, specifically the Internet, as a tool to obtain sustainable benefits. On the other hand, the Bologna Process has been requiring a major change in the pedagogical model of teaching and learning in higher education, due to the fact that it focuses on the acquisition of skills by the students and not on the mere accumulation of knowledge.

Technologically assisted learning environments are seen as fundamental support for reshaping education and can foster a more effective approach to constructive educational philosophies (Ferreira and Andrade, 2011; Sakhaei, Motaarefi, Zinalpoor and Sadagheyani, 2017; Sharpe, Beetham and Freitas, 2010).

It is clear that the current means of communication - open, social and participatory - offer great potential for transforming learning and teaching, by providing students and teachers with a range of options for communicating, collaborating and connecting - e.g. from an extensive peer network to processes of seeking information, the case of e-learning and consequently m-learning.

With regard to m-learning, Traxler (2005) considers it as an evolution of e-learning, giving importance not only to the technical characteristics and portability of mobile devices, but also to their pedagogical possibilities and advantages. He has defined it as: "any educational provision where the sole or dominant technologies are 
handheld or palmtop devices" (p. 262). Later, different actors and factors in the conceptualization process of m-learning continued to emerge (Traxler, 2007), which determine the perceptions and expectations, including in its evolutionary process towards the future (Traxler, 2009). Moreover, Traxler (2009) proposes a synthesis of the attributes of mobile learning as follows: it is penetrating and omnipresent; changes the nature of work; creates new forms of commerce; navigate through bite-size; is versatile in mobility; is a mobile hardware platform; is a "noisy" phenomenon; is a promoter of social change. In addition to these, m-learning, perceived as the learning process that occurs supported by the use of mobile devices, has as fundamental characteristic the portability of the devices and the mobility of the individuals, who may be physically and geographically distant from each other, or not, when in formal education physical spaces, such as the classroom. Thus, $\mathrm{m}$-learning was further defined as the connected, interactive and personalized use of portable devices in classrooms, collaborative learning, fieldwork, counseling and student guidance (cf. Bastos, Bauer, Cardoso, Cornelius, Mertes and Shanks, 2018; Traxler, 2011). This definition means that mobile learning may include the following technological options: smartphones, tablets, game consoles, iPods, and wireless infrastructures.

M-learning is expanding in primary and secondary education centers, as well as in higher education, with most educational institutions being aware that change is omnipresent in the lives of students, which is why it is constantly analyzed to incorporate it into their practices (Cahill, 2011). Although m-learning is innovative, technically feasible, incorporates pedagogical advantages, and currently has visibility and increasing importance in Higher Education (El-Hussein and Cronje, 2010; Traxler, 2007), it may eventually have no possibility of large-scale institutional implementation in the near future (Traxler, 2010). For m-learning in higher education to become a successful, it is important to address the social, cultural, and organizational factors involved. These can be formal and explicit, or informal and tacit, and can vary enormously across and within institutions (Traxler, 2009). In fact, higher education institutions present different disciplines with their own cultures and specific concerns, often strongly influenced by the professional practice of the "outside world" (Traxler, 2009). Adding to this problem, most of the work developed in an environment of m-learning in the universities is still in the pilot test phase, which points to considerable difficulties in the support and development of this new teaching methodologies.

Although there is a strong interest in using mobile devices to promote learning and teaching, there also seems to be a split between the promise and the reality of the use in education of this type of technology. Likewise, there is little consistency in the evidence that education has undergone drastic changes with the introduction of these devices in the classroom. This paradox, between the potential use and the actual use of technology, is known as the main object of research in an area of study that has been developed in recent years (Conole and Koskinen, 2012). Research into the design of mobile-mediated learning seeks to better understand this mismatch (Krull and Duart, 2017; Sølvberg and Rismark, 2012). Therefore, we felt the need to contribute to a study, specifically intended to reflect on the implementation of m-learning strategies in a Portuguese Polytechnic Higher Education, namely in the Lisbon Higher School of Health.

With regard to the Polytechnic Institutes in Portugal, implementing measures against info-exclusion should be considered, as it plays a fundamental role in the development of the Information Society. Almost all of them have Internet connections, allowing students to access the information they need not only on campus but also outside the campus, for instance, in their homes, through Virtual Private Network (VPN) connections. As a consequence, e-learning presents itself as a learning methodology, applied through a learning management system (that enables, for example, the administration of formative events supported by a Web technology). On the other hand, several studies carried out in the last decade, both in formal and informal contexts, report a good acceptance of the mobile technologies by the students (Cardoso and Bastos, 2018; Attwell, 2007; Kuimova, Burleigh, Uzunboylu and Bazhenov, 2018; Kukulska-Hulme, 2009; Montrieux, Vanderlinde, Schellens and De Marez, 2015; Traxler, 2010; Waycott, 2004), in collaborative learning, in fieldwork and in student mentoring (Traxler, 2005). It was in this digital environment, and based on the literature review on the role that mobile technologies can have in the individual and collaborative construction of knowledge and its educational effects, that emerged our research theme. In this text, we will focus on the part of that research, aimed at studying how the students of biomedical laboratory sciences, of the Lisbon Higher School of Health (of the Polytechnic Institute of Lisbon, Portugal), use their mobile devices. 


\section{METHODOLOGICAL OPTIONS}

\subsection{Participants}

This is a descriptive and exploratory study, so there was no formal calculation of sample size, and as such, it followed a non-probabilistic sampling process for convenience. Consequently, from the 1300 students who made up the faculty of the School of Health on the year 2015 responded to the survey 634 . The age range ranged from 18 to 45 years, with a mean of 20.78 .

\subsection{Study Design and Procedure}

As already mentioned, a descriptive and exploratory study was developed. First, it was necessary to ask the President of the Lisbon Higher School of Health for permission to carry out the research, namely the implementation of a survey. The main ethical problem in this study was the collection of potentially identifiable data. The necessary data were obtained only after informed consent of the students, to whom we explained the purpose and use of their data, after having reiterated that their participation in this survey was voluntary, ensuring full confidentiality of personal information. The informed consent took place in an online format, and from the moment of acceptance, the survey was immediately made available, which could be answered at once, or saved at a certain point and later completed. The survey had an estimated time of 10 minutes for its completion. The informed consent and inquiry were sent through a mailing list of students provided by the academic services of the Lisbon Higher School of Health. With regard to the development, access and monitoring of the survey, we worked with the Vanderbilt University's REDCap version 5.7.1 Software (https://www.project-redcap.org/). The data were later exported to the IBM SPSS software, so as to perform the statistical analysis.

\subsection{Data Collection}

In order to collect the data, a survey of 43 questions was conceived and implemented, consisting of five sections:

1. Sociodemographic characterization;

2. Characterization of the mobile device;

3. Dynamics on the use of mobile devices;

4. Perceptions on the use of mobile devices in an educational context;

5. Practices on the use of mobile devices in an educational context.

The first section allowed to obtain the sociodemographic characterization of the students participating in the research; in the other sections, it was possible to know the functionalities of the most used mobile devices and their valuation by the students in the learning process. Thus, the main goals of the survey can be summarized as indicated:

1. To demographically characterize the participants;

2. To identify the user profile of mobile devices;

3. To know the practices and perceptions of the students on the use of mobile devices in a formal educational context.

\subsection{Statistical Methods}

With regard to data analysis, we defined the level of variables that emerged from the survey. These were essentially nominal and ordinal variables. Bearing in mind the framework of variables, we used two types of statistical analysis, namely univariate and bivariate (Pestana and Gageiro, 2008).

Considering the univariate analysis, we used the descriptive statistics to describe the phenomena under study, based on the following measures:

a) Measures of central tendency: Average; Mode; Median; Average trimmed;

b) Measures of dispersion: Data amplitude; Minimum and maximum value; Standard deviation; Variance; Interquartile range;

c) Distribution measures: Kurtosis; Skewness. 


\section{RESULTS}

The results obtained on the daily use of the Mobile Device (MD) by students were analyzed in two contexts: school and non-school. With regard to the characterization of MD used by students in a non-school context, we conclude that:

- $98 \%$ of students said to have Smartphones, tablets and mobile phones;

- As far as the MD brand is concerned, Samsung prevailed (33\%) over Apple (15\%) and Nokia (10\%);

- The two most widespread operating systems were Android (70\%) and $\mathrm{iOS}(15 \%)$.

Regarding the MD user profile, the students participating in our survey showed the following general characteristics:

- having acquired the first device with a mean age of 11.12 ;

- having indicated that they most frequently write, indistinctly, on paper and mobile device (27.6\%).

The MD functionalities used by students in a non-school context can be grouped according to the relative frequency. Thus, the first grouping with frequencies between $90 \%$ and $100 \%$ relates to the following functionalities: "SMS"; "Internet"; "Alarm Clock". The second grouping with percentages included between 80\% and 90\% comprises: "Social Networks"; "Calendar"; "Record/Play Pictures". The three grouping with frequencies between $60 \%$ and $80 \%$ consists of the following functionalities: "Calculator"; "Voice Call"; "email"; "Games". Finally, the last grouping, with frequencies under $60 \%$, corresponds to the functionalities: "Record/Play Video"; "Record/Play Audio"; "MMS"; "Stopwatch"; "Radio" (Figure 1).

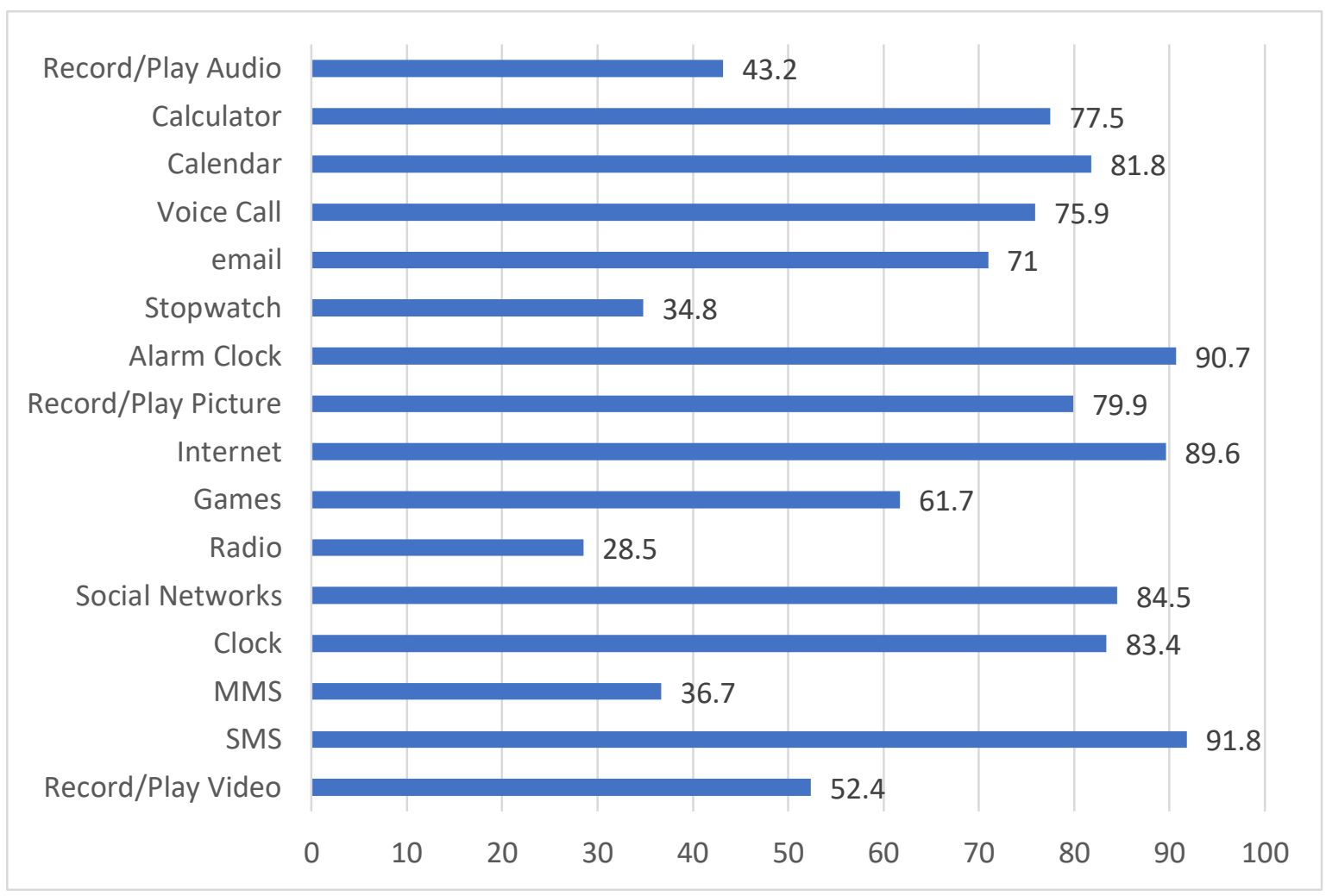

Figure 1. The MD functionalities used by students in a non-school context

Moving now to the analysis of the students' practices and perceptions on the use of MD in a school context (e.g. learning in the classroom), we can point out the following results:

- The most used MD was the Smartphone (45\%), followed by mobile phones (26\%) and Tablets $(24.1 \%)$, with the remaining values attributed to computers or no MD;

- Concerning the use of the multimedia and communication features of the mobile devices, students essentially use SMS (56\%) and email (44\%); 
- Per day, $15.5 \%$ of students use their MD for over two hours for their learning assignments. Associated with this frequency, it is also verified that $84.4 \%$ of the students nearly don't use their mobile devices to present their educational contents (below one hour per day);

- Students usually don't use mobile devices in laboratory or practical classes $(45.5 \%)$, neither in the internship seminars $(50.6 \%)$;

- From the different perceptions on the use of mobile devices, students agreed that mobile devices are useful in the classroom $(24.7 \%)$, present pedagogical advantages $(74.3 \%)$, and are real information instruments (98\%). However, despite the positive aspects stated, only $47.5 \%$ of the students agreed that the mobile devices in the classroom should be used; $46.2 \%$ of the students mentioned preferring to use them outside the classroom.

Another important fact is the perception that students have about the distraction $(66.3 \%)$ that is attributed to mobile devices during the teaching and learning process. Besides, students stated they could imagine some situation where teachers can teach better $(38 \%)$ and students learn better $(51 \%)$ through a MD. However, the relevance of mobile applications (apps) to the teaching activity was considered low by $31.9 \%$ of the students, and high by only $27.5 \%$ of them (cf. Figure 2 ).

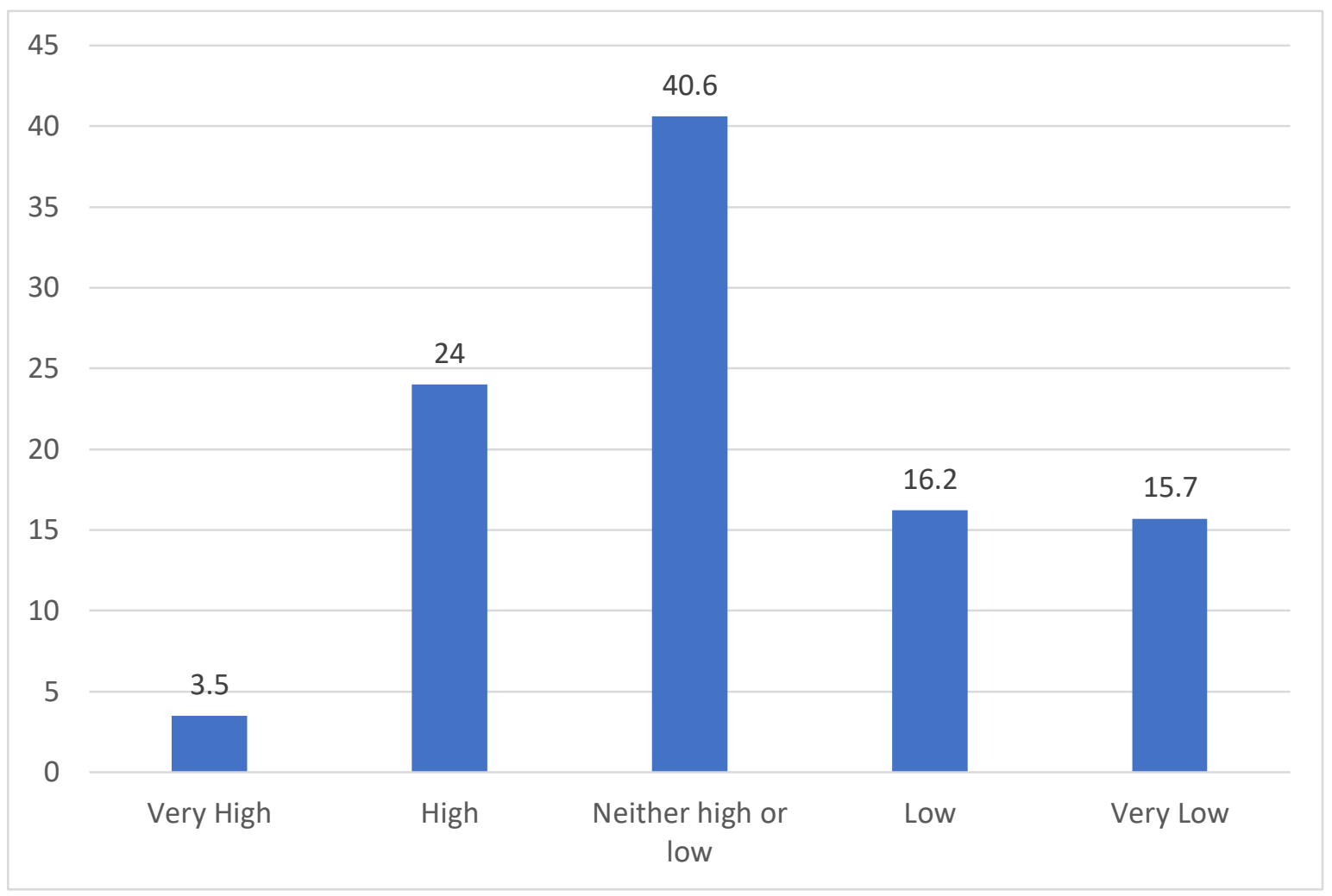

Figure 2. The relevance attributed by the students to apps for the teaching-learning process

From the analysis of the results, we can concluded that the students who answered to our survey use mobile devices as a learning tool very seldom, and only for the purposes of supporting individual (24\%) or group work $(20.2 \%)$, and clarifying doubts with teachers $(7.9 \%)$ or classmates $(4.9 \%)$.

\section{DISCUSSION AND CONCLUSION}

All the students who participated in our study acknowledged to have mobile devices, namely, most of them, Smartphones, and with the Android Operating System. These data are aligned with those presented in the literature (where results are also very close to 100\%). On the other hand, we should not forget that the penetration rate of mobile devices in the global market with the Android Operating System in the fourth quarter of 2014, according to International Data Corporation (IDC), was of 76\%, followed by iOS with 19.7\% (IDC, 
n.d.). Comparatively, the results obtained in our study show a slight decrease of $6 \%$ for the Android operating system, and about $4 \%$ in iOS. This difference may be partly due to the size of our sample.

As far as the e-learning implementation policies in Higher Education Institutions are concerned, it is important to consider the difficulties these institutions face, namely with regard to how education technology is used and whether or not it enables e-learning in Higher Education environments. In this respect, we must not forget, on the one hand, that there are differences between the learning technologies, determined by the official bodies, and the way students use the technologies outside the classroom. On the other hand, it is necessary to understand how to combine the effectiveness of the new technologies used to promote collaborative learning processes with the development of a higher order reasoning.

Our results demonstrate that participants have, according to our perspective, the two necessary conditions to become involved in mobile learning activities. The first condition is that students have shown positive perceptions about mobile devices, essentially on their ability to provide pedagogical advantages. The second condition sine qua non is that all participants have a mobile device, and there is no need to adopt a Bring Your Own Device (BYOD) strategy. This strategy may not be easy to implement: an example of this is a quantitative cross-sectional observational study that was carried out at a Dutch University. In this study, students did not seem very enthusiastic about taking their mobile devices to class, choosing instead to leave them at home, thus compromising the University's strategy, despite the didactic advantages that it could have (Kobus et al., 2013).

In addition to the having a mobile device, it is important, as recognized before, to have a positive perception about m-learning, but not only by the students. It is also essential that teachers have a positive perception about $\mathrm{m}$-learning, as is the case e.g. of one of our studies (Cardoso and Abreu, 2015) or as described in a prior research that aimed to evaluate the self-efficacy of a nursing faculty in the use of mobile technology, in the teaching and learning process in contexts of education and clinical practice (Kenny et al., 2012).

Another very important aspect to consider is the political action on the part of the Institutions of Higher Education (IHE) that should act in two fronts. The first of these is that IHE should promote online or mixed training offers, to remain competitive (cf. in the Portuguese context e.g. Peres, 2018; Peres and Mesquita, 2014). In this respect, a proposal to implement e-learning in the traditional universities of the United States of America has been presented, taking into account the concept of educational change, based on three fundamental issues: (a) Program content; (b) How to sell programmatic content within the educational community; (c) How to make a permanent assessment of its effectiveness (Cahill, 2011). The second line of political action to be considered by Higher Education Institutions is to meet the need for content open, i.e. the open educational resources repositories of Institutions in Higher Education should continue to adapt their characteristics, so that the content, the creation and publication of, the access to, and the use and reuse of learning objects can be made available from mobile devices. This action, of democratizing open content, is reflected for instance in the Horizon reports of 2004 and 2010, which referred respectively to learning objects and open content, foreseeing its short-term impact due to the current free content on the Internet that can be accessed from mobile devices (Tabuenca et al., 2012).

The importance of technology in the current and incoming generations of students, their direct implication in the classroom, combined with their potential in the learning process, is crucial to achieve academic excellence, and also to create an environment of disruption, promoter of research and innovation. Technology is not simply seen as an additive for these students, instead it is critical for them to organize and guide their own learning. Hence, technology provides, for example, a variety of interaction and communication opportunities and guarantees them the flexibility that allows them to take control in their own learning process. These generations have been and are being educated in an environment filled with (new) technologies. However, the use in learning of these technologies, and namely the mobile devices, occurs simultaneously with their use in other social and entertainment activities. And so, further research questions emerge, challenging the integration of m-learning in (health) education, to which we intend to address so as to contribute to innovative and innovating approaches, in the teaching and learning of the biomedical laboratory sciences.

\section{ACKNOWLEDGEMENTS}

Pro-rector for Pedagogical Innovation and Elearning, Open University Portugal; Mobile Learning in Higher Education (MINE) Project 2016-1-AT01-KA203-016784. 


\section{REFERENCES}

Attwell, G., 2007. Personal Learning Environments-the future of eLearning? ELearning Pap. 2, 1-8.

Bastos, G., Bauer, P., Cardoso, T., Cornelius, S.C., Mertes, K., Shanks, R.K., 2018. MINE - Mobile learning in Higher Education. IATED Academy. 10.21125/edulearn.2018.0934

Cahill, J., 2011. Implementing online or hybrid courses in a traditional university. ELearning Pap. 1-8.

Cardoso T., Abreu R., 2015. Mobile Learning and Education: Synthesis of Open Access Research. In: Zhang Y. (eds) Handbook of Mobile Teaching and Learning. Springer, Berlin, Heidelberg.

Cardoso, T., Bastos, G., 2018. Mobile learning in Higher Education: the Case of Universidade Aberta (Portugal). IATED Academy. 10.21125/edulearn.2018.0215

Conole, G., Koskinen, T., 2012. Designing for learning. ELearning Pap. 1-5.

El-Hussein, M.O.M., Cronje, J.C., 2010. Defining mobile learning in the higher education landscape. Journal of Educational Technology \& Society, 13(3). 12-21.

Ferreira, S., Andrade, A., 2011. Models and instruments for assessing Technology Enhanced Learning Environments in higher education. ELearning Pap. 1-10.

IDC: Smartphone OS Market Share [WWW Document], n.d. . www.idc.com. URL http://www.idc.com/prodserv/smartphone-os-market-share.jsp (accessed 4.10.15).

Kenny, R.F., Van Neste-Kenny, J.M., Burton, P.A., Park, C.L., Qayyum, A., 2012. Using self-efficacy to assess the readiness of nursing educators and students for mobile learning. Int. Rev. Res. Open Distance Learn. 13, $277-296$.

Kobus, M.B.W., Rietveld, P., van Ommeren, J.N., 2013. Ownership versus on-campus use of mobile IT devices by university students. Comput. Educ. 68, 29-41. https://doi.org/10.1016/j.compedu.2013.04.003

Krull, G., Duart, J., 2017. Research Trends in Mobile Learning in Higher Education: A Systematic Review of Articles (2011 - 2015). The International Review of Research in Open and Distributed Learning, 18(7). https://doi.org/10.19173/irrodl.v18i7.2893

Kuimova, M., Burleigh, D., Uzunboylu, H., Bazhenov, R., 2018. Positive Effects of Mobile Learning on Foreign Language Learning. TEM Journal, 7(4), 837-841.

Kukulska-Hulme, A., 2009. Will mobile learning change language learning? ReCall 21, 157-165. http://dx.doi.org/10.1017/S0958344009000202

Montrieux, H., Vanderlinde, R., Schellens, T., De Marez, L., 2015. Teaching and Learning with Mobile Technology: A Qualitative Explorative Study about the Introduction of Tablet Devices in Secondary Education. PLoS ONE 10(12): e0144008. https://doi.org/10.1371/journal.pone.0144008

Peres, P. 2018. O blended-Learning no contexto português do Ensino Superior: uma visão geral. Indagatio Didactica, 10 (2), 297-316. CIDTFF - Centro de Investigação em Didáctica e Tecnologia na Formação de Formadores, Universidade de Aveiro (ISSN: 1647-3582). Disponível em http://revistas.ua.pt/index.php/ID/article/view/11118/9204

Peres, P., Mesquita, A., 2014. Dimensões para a construção de um curso em b-learning: Um estudo de caso. Indagatio Didactica, 6 (1), 165-183. CIDTFF - Centro de Investigação em Didáctica e Tecnologia na Formação de Formadores, Universidade de Aveiro (ISSN: 1647-3582). Disponível em http://revistas.ua.pt/index.php/ID/article/view/2679/2532

Pestana, M.H., Gageiro, J.N., 2008. Análise de dados para ciências sociais a complementaridade do SPSS. Sílabo, Lisboa.

Sakhaei S., Motaarefi, H., Zinalpoor, S., Sadagheyani, H.E., 2017. Utilizing the information and communication technology as a learning tool for students. Ann Trop Med Public Health 2017;10:1189-94

Sharpe, R., Beetham, H., Freitas, S., 2010. Rethinking Learning for a Digital Age. How Learners are Shaping their Own Experiences. Routledge, New York. https://doi.org/10.4324/9780203852064

Sølvberg, A.M., Rismark, M., 2012. Learning spaces in mobile learning environments. Active Learning in Higher Education, 13(1), 23-33. https://doi.org/10.1177/1469787411429189

Tabuenca, B., Drachsler, H., Ternier, S., Specht, M., 2012. OER in the Mobile Era: Content Repositories' Features for Mobile Devices and Future Trends. ELearning Pap. 1-16.

Traxler, J., 2011. Aprendizagem Móvel e Recursos Educativos Digitais do Futuro. Cad. SACAUSEF VII 35-46.

Traxler, J., 2010. Students and mobile devices. ALT-J 18, 149-160. https://doi.org/10.1080/09687769.2010.492847

Traxler, J., 2009. Current state of mobile learning, in: Proceedings of the IADIS International Conference on Mobile Learning. Presented at the IADIS International Conference Mobile Learning 2005, pp. 261-270.

Traxler, J., 2007. Defining, Discussing and Evaluating Mobile Learning: The moving finger writes and having writ... Int. Rev. Res. Open Distance Learn. 8, 1-12.

Traxler, J., 2005. Defining mobile learning, in: Proceedings, IADIS International Conference on Mobile Learning, Malta. Presented at the IADS International Conference Mobile Learning 2005, Malta, pp. 261-266.

Waycott, J., 2004. The Appropriation Of PDAS As Learning And Workplace Tools: An Activity Theory Perspective. The Open University, Milton Keynes, UK. 